\title{
KAJIAN AKTIVITAS OVARIUM BABI LANDRACE DAN BABI BALI HASIL PEMOTONGAN DI RUMAH POTONG HEWAN TRADISIONAL
}

\author{
SUMARDANI N. L. G. , I W. SUBERATA, N. M. ARTININGSIH, DAN K. BUDAARSA \\ Lab. Reproduksi Ternak, Fakultas Peternakan Universitas Udayana \\ e-mail:nlg_sumardani@unud.ac.id
}

\begin{abstract}
ABSTRAK
Status reproduksi babi betina, dapat dilihat dari tingkat aktivitas ovariumnya, yang ditandai dengan adanya sejumlah folikel dan corpus luteum di dalam ovarium. Dengan mengetahui tingkat aktivitas ovarium babi betina, akan dapat dilihat tingkat performan reproduksi lainnya. Pada penelitian ini digunakan masing-masing 100 buah ovarium dari masing-masing 50 ekor babi landrace dan babi bali, yang dibagi dalam tiga kelompok bobot potong, yaitu (A) 60-70 kg; (B) 71-80 kg; dan (C) 80-90 kg. Variabel yang diamati adalah dimensi ovarium, jumlah folikel dan corpus luteum pada ovarium kanan dan kiri. Analisa data deskritif kuantitaif disertai Uji-t untuk mengetahui perbandingan antara aktivitas ovarium kanan dan kiri. Hasil penelitian menunjukkan bahwa rata-rata berat ovarium kanan dan kiri pada babi landrace adalah 5,70 $\pm 1,22 \mathrm{~g} ; 6,77 \pm 0,96 \mathrm{~g}$, dan pada babi bali adalah 4,89 $\pm 1,47 \mathrm{~g}$; 6,13 $\pm 1,46$ g. Rata-rata jumlah folikel dominan pada ovarium kanan dan kiri babi Landrace adalah 6,54 $\pm 1,81$ buah; $9,78 \pm 1,58$ buah, dan pada babi bali adalah $5,82 \pm 1,90$ buah; 8,91 $\pm 1,50$ buah. Jumlah corpus luteum pada ovarium kanan dan kiri babi landrace rata-rata 5,49 $\pm 2,22$ buah; $8,16 \pm 1.86$ buah, dan pada babi bali adalah $5,27 \pm 2,23$ buah; 7,69 $\pm 2,22$ buah. Hasil Uji-t menunjukkan bahwa rata-rata jumlah folikel dominan dan corpus luteum ovarium kiri nyata lebih banyak $(\mathrm{P}<\mathrm{O}, 05)$ dibanding ovarium kanan. Persentase folikel dominan dan corpus luteum tertinggi terdapat pada babi kelompok bobot potong (C) 80-90 kg. Kesimpulan dari penelitian ini adalah aktivitas ovarium kiri lebih aktif dibandingkan dengan aktivitas ovarium kanan, dan aktivitas ovarium berkorelasi positif terhadap berat ovarium, yang merupakan indikasi adanya aktivitas ovarium dalam memprodukai sel telur dan hormon reproduksi.
\end{abstract}

Kata kunci: aktivitas ovarium, folikel, corpus luteum, babi bali, babi landrace

\section{OVARIUM ACTIVITIES OF LANDRACE AND BALI SOWS AT TRADITIONAL SLAUGHTER HOUSING}

\begin{abstract}
The reproductive status of sows can be analyzed based on its level of ovarian activities characterized by the presence of a number of follicles and corpus luteum in the ovary. The study of level of ovarium activity of sows observed the level of other reproductive performance. In this study, 100 ovaries in each 50 Landrace and bali sows were divided into three groups of sows weighs slaughtering as of $60-70 \mathrm{~kg}(\mathrm{~A}) ; 71-80 \mathrm{~kg}(\mathrm{~B})$; and $80-90 \mathrm{~kg}(\mathrm{C})$. The variables observed were dimensions of ovary, the number of follicles and corpus luteum in the right and left ovaries. Quantitative data with quantitative t-test determines the comparison on right and left ovary activities. It showed that the average weight of right and left ovaries in landrace sows were $5.70 \pm 1.22 \mathrm{~g} ; 6.77 \pm 0.96 \mathrm{~g}$, and $4.89 \pm 1.47$ g; $6.13 \pm 1.46 \mathrm{~g}$ in bali sows. The average number of dominant follicles on the right and left ovaries of landrace sows were $6.54 \pm 1.81 \mathrm{f}$ follicles; $9.78 \pm 1.58$ follicles, and on bali sows is $5.82 \pm 1.90$ follicles; $8.91 \pm 1.50$ follicles. The number of corpus luteum on the right and left ovaries of the Landrace were 5.49 $\pm 2.22 \mathrm{CL} ; 8.16 \pm 1.86 \mathrm{CL}$, and on bali sows is $5.27 \pm 2.23 \mathrm{CL} ; 7.69 \pm 2.22 \mathrm{CL}$. The t-test results showed that average number of dominant follicles and corpus luteum in left ovary were significantly greater $(\mathrm{P}<0.05)$ compared to the right ovary. The highest percentage of dominant follicles and corpus found in sows of slaughter grouping 80-90 kg (C). It can be concluded that left ovary activity was more active than right ovary, and ovarian activity positively correlated with ovarian weight which indicating ovarian activity in egg cell production and reproductive hormone.
\end{abstract}

Keywords: ovarium activity, follicle, corpus luteum, bali sows, landrace pig 


\section{PENDAHULUAN}

Babi merupakan hewan yang telah dipelihara dan dikembangkan sejak dahulu untuk tujuan memenuhi kebutuhan akan daging bagi umat manusia. Babi merupakan salah satu komoditas ternak penghasil dagingyang memiliki potensi besar untuk dikembangkan karena memiliki sifat-sifat dan kemampuan yang menguntungkan antara lain: laju petumbuhan yang cepat, jumlah anak per kelahiran (litter size) yang tinggi, efisiensi ransum yang baik (70-80\%), dan persentase karkas yang tinggi (65-80\%) (Siagian, 1999). Selain itu, babi mampu memanfaatkan sisa-sisa makanan atau limbah pertanian menjadi daging yang bermutu tinggi. Karakteristik reproduksinya unik bila dibandingkan dengan ternak sapi, domba dan kuda, karena babi merupakan hewan yang memiliki sifat prolifik yaitu jumlah perkelahiran yang tinggi (10-14 ekor/kelahiran), serta jarak antara satu kelahirann dengan kelahiran berikutnya pendek (Sihombing, 2006).

Dalam usaha pengembangan dan peningkatan produktivitas babi baik babi ras maupun lokal, performans reproduksi memegang peranan penting dikaitkan dengan usaha peningkatan produksi ternak babi tersebut. Performans reproduksi babi betina sangat penting diketahui untuk memudahkan mencapai tujuan tersebut, mengingat peranan induk babi dalam memproduksi bibit babi sangat penting. Babi betina mampu menghasilkan anak sekitar 10-14 ekor per kelahiran (Toelihere, 1993; Feradis, 2010). Hal ini berkaitan erat dengan kondisi organ reproduksi babi betina, khususnya kemampuan dari aktivitas ovarium dalam memproduksi sel telur.

Ovarium merupakan organ reproduksi primer pada babi betina yang dapat menghasilkan sel telur dan hormon. Sel telur akan berkembang di dalam ovarium sejalan dengan pertumbuhan folikel yang membungkusnya. Folikel akan tumbuh dari folikel primordial, primer, sekunder, hingga mencapai folikel dominan dan folikel de Graaf, yang siap diovulasikan (Hafez dan Hafez, 2000). Selanjutnya setelah ovulasi, pada bagian ovarium yang terjadi ovulasi akan terbentuk corpus haemoragicum dan corpus luteum (Feradis 2010). Keberadaan folikel dominan dan corpus luteum pada ovarium merupakan penentu dari ada tidaknya aktivitas ovarium, yang memiliki makna sejalan dengan bisa atau tidaknya induk babi memproduksi anak atau bibit babi, dan kondisi ini hanya ada pada babi betina yang mempunyai siklus reproduksi normal. Pada induk babi yang mengalami gangguan reproduksi, khusunya gangguan folikulogenesis, maka tidak akan terbentuk folikel dominan. Demikian juga halnya pada babi betina yang mengalami ganngguan ovulasi karena kurangnya hormon luteinizing hormone (LH) tidak akan mencapai terbentuknya corpus luteum di dalam ovariumnya.

Babi merupakan hewan yang telah dipelihara dan dikembangkan sejak dahulu untuk tujuan memenuhi kebutuhan akan daging bagi umat manusia. Secara umum, pemeliharaan ternak babi relatif mudah karena babi mempunyai toleransi yang tinggi terhadap kondisi iklim yang beragam, dan dapat memanfaatkan berbagai jenis sumber pakan, sehingga tidak jarang babi diberi makan sisa-sisa makanan manusia atau berbagai jenis limbah. Selain itu, babi merupakan hewan yang mampu menghasilkan banyak anak dalam setahun (prolifik) dengan interval generasi yang lebih singkat, sehingga babi berpotensi sebagai ternak komersial. Menurut Siagian (1999) bahwa ternak babi memiliki laju petumbuhan yang cepat, jumlah anak per kelahiran (litter size) yang tinggi, efisien ransum yang baik (70$80 \%)$, dan persentase karkas yang tinggi (65-80\%).

Dalam usaha pengembangan dan peningkatan produktivitas babi, performans reproduksi memegang peranan penting dikaitkan dengan usaha peningkatan produksi ternak babi tersebut. Performans reproduksi tersebut meliputi: siklus estrus, tanda-tanda estrus, lama kebuntingan, litter size, farrowing rate, umur sapih, dan berat sapih. Produktivitas seekor induk babi ditentukan utamanya oleh jumlah anak yang lahir seperindukan (litter size) dan oleh angka melahirkan anak (farrowing rate) dalam setahunnya. Makin tinggi litter size dan farrowing rate dari seekor induk, dapat diharapkan makin tinggi pula produktivitasnya dalam setahun atau selama umur reproduksi induk tersebut (Ardana dan Putra, 2008).

Menurut Toelihere (1993) dan Feradis (2010) bahwa seekor babi betina mencapai pubertas pada umur 5-8 bulan dan umur dianjurkan untuk perkawinan pertama adalah 8-10 bulan. Sedangkan babi jantan dibiarkan mencapai umur 8-9 bulan sebelum dipakai untuk mengawini babi betina. Babi betina memiliki siklus estrus rata-rata 21 hari dan lama estrus 2-3 hari dengan angka ovulasi 10-20 sel telur. Lama kebuntingan pada babi rata-rata 114 hari dan induk mengalami estrus kembali setelah 4-7 hari sesudah penyapihan.

Organ reproduksi betina terdiri atas organ reproduksi primer dan organ reproduksi sekunder. Organ reproduksi primer adalah ovarium, sedangkan organ reproduksi sekunder adalah saluran reproduksi yang terdiri dari tuba fallopii (oviduct), uterus, serviks, vagina dan vulva. Fungsi organ sekunder ini adalah menerim dan menyalurkan sel-sel kelamin jantan dan betina, memberi makan dan melahirkan individu baru (Toelihere, 1993).

Ovarium adalah alat reproduksi primer karena berfungsi sebagai penghasil sel telur (ovum) dan hormon (estrogen dan progesteron). Ukurannya sangat bergantung pada umur dan status reproduksi betina, sedan- 
gkan bentuknya bervariasi sesuai dengan species. Dua komponen pada ovarium yang sangat penting adalah folikel dominan dan korpus luteum (Adelin, 2001).

Sel telur akan berkembang di dalam ovarium sejalan dengan pertumbuhan folikel yang membungkusnya. Folikel akan tumbuh dari folikel primordial, primer, sekunder, hingga mencapai folikel dominan dan folikel de Graaf, yang siap diovulasikan (Hafez dan Hafez, 2000). Selanjutnya setelah ovulasi, pada bagian ovarium yang terjadi ovulasi akan terbentuk corpus haemoragicum dan corpus luteum (Feradis 2010). Keberadaan folikel dominan dan corpus luteum pada ovarium merupakan penentu dari ada tidaknya aktivitas ovarium, yang memiliki makna sejalan dengan bisa atau tidaknya induk babi memproduksi anak atau bibit babi, dan kondisi ini hanya ada pada babi betina yang mempunyai siklus reproduksi normal. Induk babi yang mengalami gangguan reproduksi, khusunya gangguan folikulogenesis, maka tidak akan terbentuk folikel dominan.

Hormon yang dihasilkan oleh ovarium adalah estrogen dari sel-sel folikel dan progesteron dari selsel corpus luteum. Hormon ini berperan penting dalam menyiapkan alat-alat reproduksi untuk kebuntingan dan memelihara kebuntingan sampai melahirkan anak. Proses produksi hormon ovarium dikendalikan oleh hormon gonadotropin dari hipofise seperti: FSH, LH, LTH atau prolaktin yang merangsang pertumbuhan folikel, menyebabkan ovulasi dan pembentukan corpus luteum serta menyebabkan corpus luteum bersekresi (Djanuar, 1985). Pada induk babi yang mengalami gangguan reproduksi, khusunya gangguan ovulasi karena kurangnya hormon Luteinizing Hormone (LH) maka tidak akan mencapai terbentuknya corpus luteum di dalam ovariumnya.

Bentuk dan ukuran ovarium berbeda-beda menurut species dan fase siklus berahi ternak betina. Pada babi, ovarium berupa gumpalan anggur, folikel-folikel dan corpus luteum menutupi jaringan-jaringan ovarial dibawahnya. Bagian ovarium yang tidak bertaut pada mesovarium menonjol kedalam cavum abdominalis. Pada permukaan inilah folikel ovarii menjulang keluar. Menurut Toelihere (1993) dinyatakan bahwa ovarium babi berbentuk lonjong dan menyerupai buah anggur karena banyaknya folikel dan atau corpus luteum. Berat ovarium mencapai 3,0 - 7,0 gram. Folikel babi secara normal berdiameter $8,0-12,0 \mathrm{~mm}$, dan corpus luteum berkisar 10,0 - 15,0 mm. Lokasi ovarium pada babi kira-kira sama dengan sapi, dan karena ligamentum lata yang panjang menyebabkan lokasi ovarium di dalam rongga perut pada babi-babi betina tua sangat bervariasi. Ovarium babi hampir seluruhnya ditutup di dalam bursa ovarii oleh mesosalpinx. Hasil penelitian yang sejalan mengenai ovarium, dinyatakan oleh
Suberata et al. (2016), dan usaha peningkatan jumlah sel telur yang diovulasikan dapat dilakukan dengan beberapa metode, seperti metode steaming up dan flushing (Sumardani, 2010).

Informasi tentang status reproduksi babi betina, baik itu babi lokal (babi bali) maupun babi ras, yang dipotong di beberapa rumah potong hewan (RPH) tradisional, masih sangat sedikit bahkan kurang, sehingga diperlukan penelitian untuk mengetahui status reproduksi babi betina tersebut berdasarkan aktivitas ovarium.

Berdasarkan hal tersebut diatas, penelitian ini dilakukan untuk mengetahui status reproduksi babi betina (babi bali dan babi ras, landrace) berdasarkan aktivitas ovarium, dan untuk menambah informasi tentang status reproduksi babi betina yang dipotong pada rumah potong hewan tradisional.

\section{METODE PENELITIAN}

\section{Persiapan Sampel}

- Ovarium babi diperoleh dari beberapa rumah potong hewan tradisional dan selanjutnya dibawa langsung ke laboratorium menggunakan medium $\mathrm{NaCl}$ fisiologis (0,9\%) dalam waktu yang tidak lebih dari satu jam.

- Jumlah ovarium yang digunakan adalah masingmasing 100 buah yang diperoleh dari 50 ekor babi bali dan 50 ekor babi Landrace.

- Ovarium yang diambil tersebut masih bersatu dengan organ reproduksi lainnya sehingga harus dipisahkan menggunakan gunting dan pisau preparat.

- Ovarium tersebut dikelompokkan berdasarkan bobot babi yang telah ditandai sebelumnya pada saat pengambilan sampel di RPH.

- Pengelompokan bobot babi betina meliputi: A (60-70 kg), B (71-80 kg), C (81-90 kg),

\section{Variabel yang Diamati}

- Setiap pasang ovarium ditempatkan pada petridish yang berisi medium $\mathrm{NaCl}$ fisiologis.

- Variabel yang diamati meliputi: berat ovarium, jumlah folikel dominan dan corpus luteum pada ovarium.

- Berat ovarium diketahui dengan cara menimbang setiap ovarium menggunakan timbangan digital.

- Jumlah folikel dominan dan corpus luteum dihitung secara langsung pada permukaan ovarium.

\section{Alur Penelitian}

Untuk lebih mempermudah dalam pelaksanaan penelitian maka dibuat alur penelitian yang ditunjukkan dengan bagan alur penelitian pada Gambar 1. 


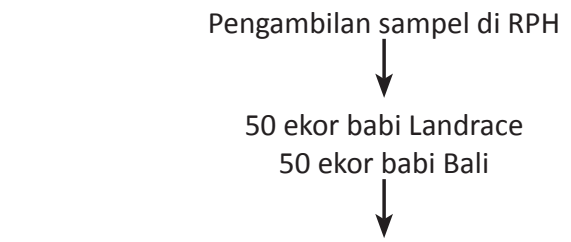

Pemilahan sampel berdasarkan kelompok bobot badan $(\mathrm{kg})$ A (60-70), B (71-80), C (81-90)

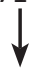

Pengolahan sampel di Laboratorium

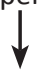

Pemilahan ovarium dari organ reproduksi lainnya

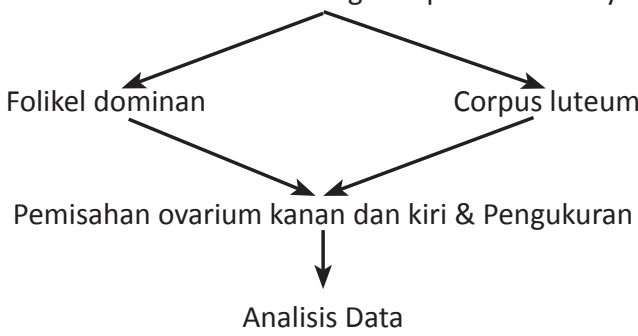

Gambar 1. Diagram alir penelitian.

\section{Analisis Data}

Data yang dikumpulkan selanjutnya ditabulasikan, dan dianalisis menggunakan analisis deskritif kuantitatif. Perbandingan antara ovarium kanan dan kiri menggunakan uji t (T-test) menurut Steel dan Torrie (1993) dan Sudijono (2008).

\section{HASIL DAN PEMBAHASAN}

\section{Rumah Potong Hewan Tradisional}

Penelitian ini dilaksanakan secara bertahap, yang diawali dengan penentuan lokasi pengambilan sampel ovarium babi di rumah potong hewan, yang dikelola secara mandiri/tradisional. Sampel ovarium babi, berasal dari dua jenis babi yaitu babi ras (landrace) dan babi bali. Berdasarkan hasil survei di wilayah Kabupaten Gianyar, yang meliputi Gianyar Utara, Timur dan Barat, maka diperoleh data bahwa tempattempat pemotongan ternak babi ras tersebut lebih dominan berada di wilayah Gianyar Utara dan Barat. Hal ini dimungkinkan karena wilayah Gianyar Utara masih didominasi adanya lahan pertanian, sehingga adanya limbah-limbah hasil pertanian tersebut dapat dimanfaatkan sebagai pakan ternak. Hal tersebut mendukung petani/peternak untuk memelihara ternak babi baik dalam skala kecil maupun menengah, disamping juga memelihara ternak-ternak yang lainnya, yang memanfaatkan limbah hasil pertanian tersebut. Demikian pula dengan wilayah Gianyar Barat, yang berbatasan langsung dengan Kabupaten Tabanan, yang juga merupakan wilayah pertanian terluas di
Bali, petani/peternak juga memelihara ternak babi dan ternak-ternak lainnya, dimana pakan ternak dapat diperoleh dengan mudah dan murah dari limbah-limbah hasil pertanian tersebut. Oleh karena itu, pengambilan sampel ovarium babi ras di rumah potong tradisional/ mandiri lebih diarahkan pada wilayah Gianyar Utara dan Gianyar Barat. Disamping itu juga, berdasarkan hasil survei, diperoleh data bahwa pemeliharaan babi bali dominan berada pada deerah-daerah kering, seperti wilayah Karangasem, Buleleng, dan Pulau Nusa Penida, sehingga beberapa sampel ovarium babi bali, diperoleh pada daerah-daerah tersebut, disamping juga ada beberapa sampel yang diperolah di wilayah Karangasem, mengingat distribusi dan peminat daging babi guling yang berasal dari babi bali, didominasi oleh pedagang-pedagang babi guling di wilayah Gianyar dan Badung juga Denpasar.

Pengambilan sampel ovarium dilakukan pada 100 ekor induk babi (50 ekor babi bali dan 50 ekor babi landrace), yang berarti jumlah sampel ovarium yang diperoleh adalah masing-masing 100 buah. Pengambilan sampel ovarium juga dilakukan bertahap, mengingat jumlah ternak babi betina yang dipotong tidak secara serentak dalam jumlah besar, dan juga ternak babi yang dipotong didominasi oleh ternak jantan kastrasi. Hal lain juga yang menyebabkan pengambilan sampel secara bertahap adalah jadwal pemotongan ternak babi yang dilakukan di rumah potong hewan tradisional/ mandiri tersebut tidak teratur atau tidak secara rutin, tergantung pada jumlah pesanan yang masuk, dan ada tidaknya hari raya adat/agama yang berlangsung. Oleh karena itu, pengambilan sampel dilakukan secara bertahap oleh dua tim, sampai dengan enam kali pengambilan sampel, seperti yang tercantum dalam jadwal pengambilan sampel di bawah ini:

Tabel 1. Jadwal pengambilan sampel (ovarium babi betina)

\begin{tabular}{cccc}
\hline No. & Tanggal & $\begin{array}{c}\text { Jumlah Induk } \\
\text { Babi Bali (ekor) }\end{array}$ & $\begin{array}{c}\text { Jumlah Induk } \\
\text { Babi Landrace (ekor) }\end{array}$ \\
\hline 1 & 13 April 2017 & 10 & 10 \\
2 & 14 April 2017 & 10 & 10 \\
3 & 28 Mei 2017 & 10 & 10 \\
4 & 23 Juni 2017 & 10 & 10 \\
5 & 03 Juli 2017 & 4 & 10 \\
6 & 28 Juli 2017 & 6 & 0 \\
& Total & 50 & 50 \\
\hline
\end{tabular}

Dalam pelaksanaan penelitian pemilihan dan pengelompokan sampel dilaksanakan berdasarkan bobot badan (bobot potong) induk tersebut yaitu: A (60-70 kg); B (71-80 kg); dan C (81-90 kg).

\section{Berat Ovarium}

Pengamatan ovarium dilaksanakan di Laboratorium Reproduksi Ternak dan Laboratorium Teknologi Hasil 

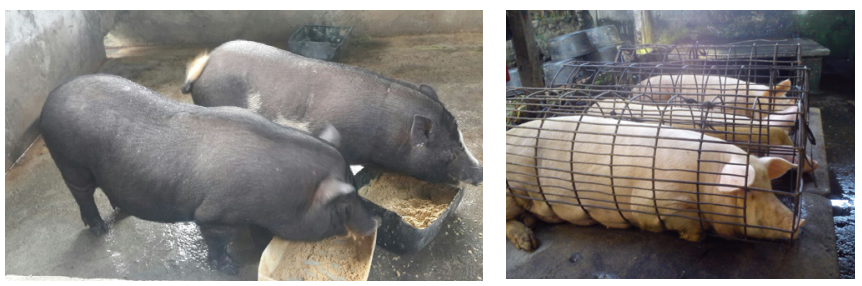

Gambar 2. Babi betina yang siap untuk dipotong, babi bali (hitam) dan babi ras (putih)
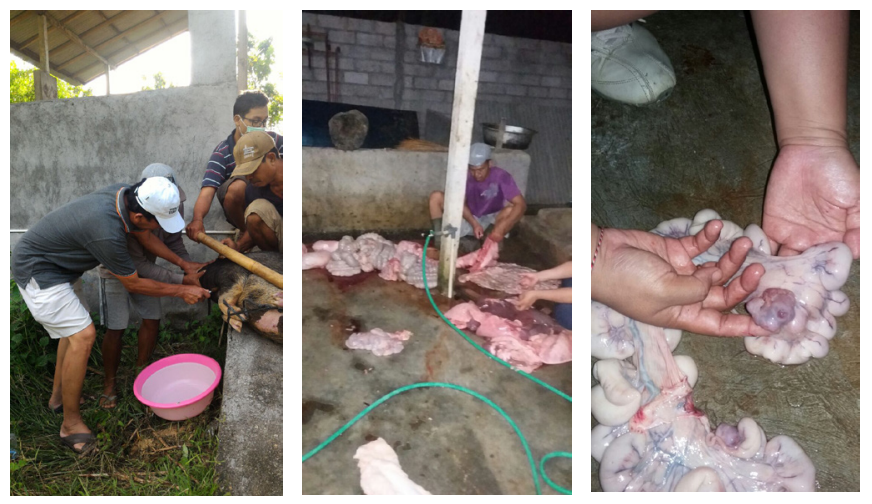

Gambar 3. Proses pemotongan babi dan pemilahan organ reproduksi
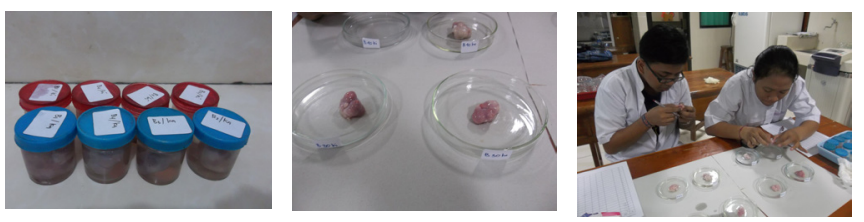

Gambar 4. Pengamatan ovarium babi - folikel dan corpus luteum

Ternak Fakultas Peternakan Universitas Udayana, di Denpasar, dibantu oleh dua orang mahasiswa.

Hasil penelitian menunjukkan bahwa rataan berat ovarium tertinggi terdapat pada kelompok babi betina yang berbobot 81-90 kg (Tabel 2). Hal ini disebabkan oleh tingkat aktivitas ovarium tertinggi tercapai pada umur di atas 7 bulan dengan bobot $80-90 \mathrm{~kg}$. Pada periode ini, organ reprodukais telah berkembang dan siap untuk bereproduksi secara sempurna. Menurut Toelihere (1993) dinyatakan bahwa ovarium babi berbentuk lonjong dan menyerupai buah anggur karena banyaknya folikel dan atau corpus luteum. Berat ovarium mencapai 3,0-7,0 gram. Pada hasil penelitian Suberata et al. (2016), dinyatakan bahwa ovarium kiri babi Landrcae lebih berat dibandingkan dengan ovarium kanan babi Landrace. Dalam penelitian ini, yang juga mengamati ovarium pada babi bali, menunjukkna bahwa ovarium babi bali kiri umumnya lebih berat dibandingkan dengan ovarium babi bali kanan. Hal ini menunjukkan bahwa aktivitas ovarium kiri lebih aktif dibandingkan dengan aktifitas ovarium kanan. Berat ovarium merupakan indikasi adanya aktivitas ovarium dalam memprodukai sel telur dan hormon reproduksi. Semakin aktif ovarium tersebut akan berkorelasi positif terhadap berat ovarium.

\section{Jumlah Folikel dan Corpus Luteum}

Hasil penelitian menunjukkan bahwa secara umum jumlah folikel dominan dan corpus luteum pada ovarium kiri babi betina baik babi ras maupun babi bali lebih banyak dibandingkan dengan ovarium kanan untuk semua kelompok bobot badan babi betina yang dipotong (Tabel 2). Dari hasil analisa menunjukkan bahwa kelompok babi betina dengan bobot badan 60$70 \mathrm{~kg}$ (A), 71-80 kg (B), dan 81-90 kg (C) mempunyai jumlah folikel dominan ovarium kiri yang nyata lebih banyak $(\mathrm{P}<0,05)$ dibandingkan dengan jumlah folikel dominan pada ovarium kanan. Sedangkan untuk jumlah corpus luteum pada ovarium kiri nyata lebih banyak $(\mathrm{P}<0,05)$ dibandingkan dengan jumlah corpus luteum pada ovarium kanan. Hal ini dimungkinkan oleh adanya aktivitas ovarium dalam memproduksi sel telur dan hormon reproduksi. Semakin aktif ovarium akan berkorelasi positif terhadap berat ovarium dan juga jumlah folikel yang terbentuk.

Banyaknya jumlah folikel dominan tidak sejalan dengan banyaknya jumlah corpus luteum yang dihasilkan. Hal ini dapat disebabkan oleh adanya folikel dominan yang tidak berhasil diovulasikan sehingga

Tabel 2. Rataan hasil pengamatan ovarium babi betina

\begin{tabular}{|c|c|c|c|c|c|}
\hline \multirow{2}{*}{ Pengamatan } & \multirow{2}{*}{ KIp } & \multicolumn{2}{|c|}{ Babi Landrace } & \multicolumn{2}{|c|}{ Babi Bali } \\
\hline & & Kanan & Kiri & Kanan & Kiri \\
\hline \multirow[t]{3}{*}{ Berat ovarium (g) } & $A$ & $4,42 \pm 0,45$ & $5,74 \pm 0,56$ & $3,36 \pm 0,47$ & $4,75 \pm 0,58$ \\
\hline & B & $5,85 \pm 0,60$ & $6,92 \pm 0,91$ & $5,03 \pm 0,63$ & $5,98 \pm 0,86$ \\
\hline & C & $6,84 \pm 0,88$ & $7,65 \pm 0,96$ & $6,29 \pm 0,81$ & $7,65 \pm 0,96$ \\
\hline Rataan & & $5,70 \pm 1,22$ & $6,77 \pm 0,96$ & $4,89 \pm 1,47$ & $6,13 \pm 1,46$ \\
\hline \multirow[t]{3}{*}{ Jumlah Folikel (buah) } & $A$ & $4,87 \pm 1,12$ & $8,13 \pm 2,64$ & $4,00 \pm 2,42$ & $7,20 \pm 2,42$ \\
\hline & $B$ & $6,27 \pm 2,18$ & $9,93 \pm 2,63$ & $5,67 \pm 2,22$ & $9,53 \pm 2,32$ \\
\hline & $\mathrm{C}$ & $8,47 \pm 2,41$ & $11,27 \pm 2,25^{b}$ & $7,80 \pm 2,33$ & $10,00 \pm 1,77^{b}$ \\
\hline Rataan & & $6,54 \pm 1,81$ & $9,78 \pm 1,58$ & $5,82 \pm 1,90$ & $8,91 \pm 1,50$ \\
\hline \multirow[t]{3}{*}{ Jumlah Corpus Luteum (buah) } & $A$ & $3,00 \pm 1,06$ & $5,93 \pm 1,94$ & $2,80 \pm 0,86$ & $5,13 \pm 1,76$ \\
\hline & B & $6,20 \pm 1,52$ & $9,33 \pm 1,91$ & $5,87 \pm 1,60$ & $8,87 \pm 2,32$ \\
\hline & C & $7,27 \pm 1,62$ & $8,93 \pm 1,86$ & $7,13 \pm 1,80$ & $9,07 \pm 1,87$ \\
\hline Rataan & & $5,49 \pm 2,22$ & $8,06 \pm 1,86$ & $5,27 \pm 2,23$ & $7,69 \pm 2,22$ \\
\hline
\end{tabular}

Keterangan: A: Bobot induk 60-70 kg; B: Bobot induk $71-80 \mathrm{~kg}$; : Bobot induk $81-90 \mathrm{~kg}$ 
jumlah corpus luteum berkurang. Hal ini sejalan dengan pendapat Cambell et al. (2000) yang menyatakan bahwa banyaknya folikel yang mengalami atresia sebelum berkembang sampai dewasa dan rusaknya dinding folikel dapat menunda terjadinya ovulasi. Hasil yang sama juga diperolah dalam penelitian Suberata et al. (2016).

Dalam penelitian ini, baik babi ras maupun babi bali menunjukkan hasil yang sejalan, dimana aktivitas ovarium kiri lebih tinggi dibandingkan dengan aktivitas ovarium kanan, sehingga mempengaruhi berat ovarium serta jumlah folikel yang terbentuk. Aktivitas ovarium pada ternak babi betina yang sudah pubertas, akan meningkat menjelang fase estrus (fase birahi). Adanya folikel yang terbentuk di dalam ovarium menunjukkan tingkat kesuburan dari ternak babi betina tersebut. Semakin banyak folikel yang terbentuk mengindikasikan semakin tinggi tingkat kesuburan dari ternak tersebut.

\section{SIMPULAN}

Dari hasil penelitian, dapat disimpulkan bahwa rataan tertinggi jumlah folikel dominan dan corpus luteum terdapat pada ovarium kiri, yang menandakan bahwa ovarium kiri lebih aktif dibandingkan dengan ovarium kanan. Secara keseluruhan (berat ovarium, jumlah folikel dominan, dan jumlah corpus luteum) tertinggi pada babi ras maupun babi bali dengan bobot badan 81-90 kg mengindikasikan bahwa sistem reproduksi pada kelompok babi betina tersebut telah mampu bereproduksi dengan baik.

\section{SARAN}

Diperlukan penelitian lebih lanjut untuk menganalisa ovarium babi betina, untuk mengetahui lebih dalam lagi tentang aktivitas ovarium babi betina dari kajian biomolekuler.

\section{UCAPAN TERIMAKASIH}

Terimakasih kepada Universitas Udayana (Fakultas Peternakan Universitas Udayana) atas dana penelitian Hibah Unggulan Program Studi (HUPS) Tahun Anggaran 2017 sehingga penelitian ini dapat dilaksanakan dengan baik.

\section{DAFTAR PUSTAKA}

Adelin, T. E. 2001. Pola Estradiol dan Progesteron Serum pada Tikus yang Disuperovulasi dikaitkan dengan Kinerja Reproduksi selama Kebuntingan. Disertasi Program Pasca Sarjana Institut Pertanian Bogor.

Ardana, I. B. dan D. K. H. Putra. 2008. Ternak Babi Manajemen Reproduksi, Produksi dan Penyakit. Udayana University Press. Denpasar.

Djanuar, R. 1985. Fisiologi Reproduksi dan Inseminasi Buatan pada Sapi. Gajah Mada University Press. Yogyakarta.

Feradis. 2010. Reproduksi Ternak. Alfabeta. Bandung.

Hafez, B. dan Hafez E. S. E. 2000. Reproductive Behavior. In: Hafez E. S. E., Hafez B, editor. Reproduction in farm Animals. $7^{\text {th }}$ Ed. USA: Williams dan Wilkins. http://ojs.unud.ac.id/index.php/mip/article/ view/21467/141999

http://ojs.unud.ac.id/index.php/mip/article/ view/9206/6945

Siagian H. P. 1999. Manajemen Ternak Babi. Diktat Kuliah Jurusan Ilmu Produksi Ternak. Fakultas Peternakan Institut Pertanian Bogor, Bogor.

Sihombing, D. T. H. 2006. Ilmu Ternak Babi. Ed.2. Gadjah Mada University Press. Bulaksumur, Yogyakarta 55281.

Steel, R. G. D., dan J. H. Torrie. 1993. Prinsip dan Prosedur Statistika (terjemahan). PT Gramedia Pustaka Utama. Jakarta.

Suberata, I W., N. L. G. Sumardani, dan N. M. Artiningsih. 2016. Kajian aktivitas ovarium babi betina hasil pemotongan di rumah potong hewan tradisional. Majalah Ilmiah Peternakan. 19(2) 2016: 80-83.

Sudijono, A. 2008. Pengantar Statistika Pendidikan. Raja Grafindo. Jakarta.

Sumardani, N. L. G., D. A. Warmadewi, I N. T. Ariana, dan R. R. Indrawati. 2010. Kombinasi metode steaming-up danflushing dalam meningkatkan litter size babi landrace. Majalah Ilmiah Peternakan. 13(3) 2010: 94-97.

Toelihere M.R. 1993. Inseminasi Buatan pada Ternak. Angkasa. Bandung. 